\title{
Peertechz
}
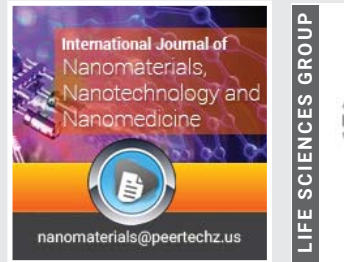

Nanomaterials, Nanotechnology and Nanomedicine 2 somscecss

Review Article

\section{Discussion on the influence of} nanoparticle characteristics in New Coronavirus Disease-19 and severe acute respiratory syndrome Coronavirus 2

\section{ISSN: $2455-3492$}

Received: 21 January, 2021

Accepted: 30 March, 2021

Published: 31 March, 2021

*Corresponding author: Shenguo Wang, Institute of Chemistry, Chinese Academy of Sciences, Beijing 100190, China, E-mail: wangsg@iccas.ac.an

Keywords: Virus; COVID-19; Nanoparticles; Size; Penetration; Toxicity; Infection

https://www.peertechzpublications.com

Check for updates

\section{Shenguo Wang*}

Institute of Chemistry, Chinese Academy of Sciences, Beijing 100190, China

\begin{abstract}
In the paper, why New Coronavirus Disease-19 (COVID-19) should belong to a class of protein nanoparticle and possessed ultra-small size and super-penetration capability, as well as effect of the COVID-19 characteristic on follows phenomena were discussed. (1) The difference existed on toxicity, transmission speed and diffusion range of the COVID-19 and Severe acute respiratory syndrome (Sars) virus. (2) The different time interval between COVID-19 infection and discover existed in different person. (3) The different time interval in "new crown virus infection", "asymptomatic infection", "suspected case" and "re-infection" produced existed in different person. (4) The different time interval from COVID-19 infection to produce SARS-CoV-2 disease existed in different person. The improve methods and suggestion for avoiding and preventing COVID-19 infection and treating SARS-CoV-2 were proposed.
\end{abstract}

\section{Abbreviations}

COVID-19: New Coronavirus Disease -19; SARS-CoV-2: Severe acute respiratory syndrome coronavirus 2; SARS: Severe Acute Respiratory Syndrome; VUI-202103/01: Mutant New Coronavirus

Ever since the discovery of Coronavirus disease 2019 (COVID-19) (Figure 1) [1], it has spread to more than 230 countries and regions in the world, in the term of September of 2019 to March 19 of 2021, more than 122 million people had been diagnosed with infection, of which more than 22 million had died [2], the COVID-19 has become the most serious disaster in the world in recent decades. So, the study of the infection characteristics and transmission routes of the COVID-19, as well as the research on the immune vaccine and drug control methods and methods of the COVID-19, had been also greatly promoted.

Although there are many research reports on specialties of toxicity, transmission, latent and re-positive properties of the COVID-19, as well as on the prevention and treatment of the COVID-19, but most of them were discussed from the point of view of virology, epidemiology, immunology, pathophysiology, structural proteins and other medical specialties, but it is few

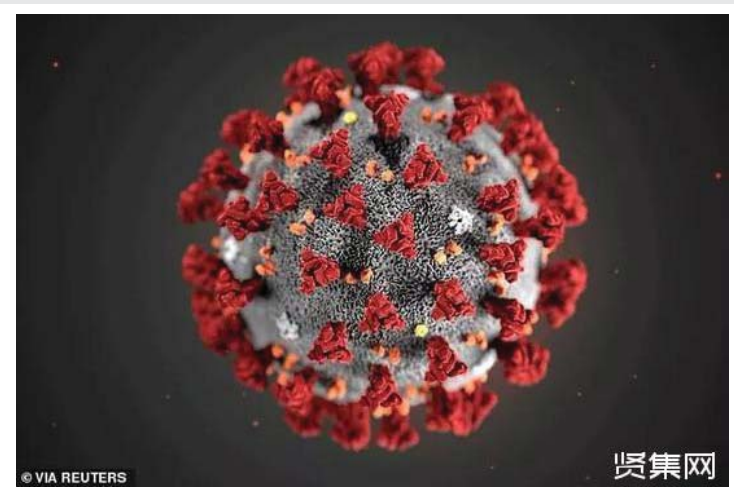

Figure 1: COVID-19 [1]. 
considering the possible effects on physical geometry of the COVID-19's size on the transmission, latency, re-positive and variation of the COVID-19 [3]. Considering the toxicity of a virus to the human has affected by many factors including pathophysiology, structural proteins, affinity and size of both of the viruses, etc., so that based on the characteristics of ultra-small size of the COVID-19, to discuss possible effects of physical geometric effects of size of COVID-19 on toxicity, transmission, latency, re-positive and variation of the COVID-19 is necessary.

It is well known that nanoparticles are a class of "solid particles of nanometer size (1 100nm)", which possess many characteristics such as ultra-small size, large specific surface and super-penetration capability etc. [4-14], that can't be found on general other materials. Because the smaller the particle size, the more penetrating the nanoparticles will drill into different tissues and organs: the larger nanoparticles will be swallowed by white blood cells, while the smaller nanoparticles will reach different tissues and organs within the spleen, bone marrow and liver through the lymphatic system (Table 1). As a result, nanoparticles have shown potential application prospects in biomedical field. However, on another hand the potential biosafety risks caused by the ultra-small particle size and supernormal penetration of nanoparticles have also attracted great attention [15-17]. So that, Food and Drug Administration (FDA) around the world have developed targeted nanoparticle biosafety registration standards for medical devices and biomedical preparations containing nanoparticles.

Based on the reported that diameter of COVID-19 is in the scope of $60 \sim 140 \mathrm{~nm}$, that is just within the defined size range of nanoparticles, so it can be considered that COVID-19 is also a class of nanoparticles, and it should belong a class of protein nanoparticles. In this case, the COVID-19 should possess common characteristics of all nanoparticles that the super-penetration capability and the super-large specific surface. Therefore, people also need to pay attention on possibly hidden biosafety dangers caused by ultra-small size and super-penetration capability of the COVID-19 [15]. Due to the consideration above, the author thinks that during analysis of characteristics and hazards of the COVID-19, the RNA molecule on toxicity, transmission, incubation, renaturation and variation of the COVID-19, the people need to consider not

Table 1: Different sizes particles can reach location in vivo [21]

\begin{tabular}{|c|c|}
\hline Particle size & Can reach the location in vivo \\
\hline$>12 \mathrm{~mm}$ & $\begin{array}{l}\text { Can be blocked at the end of the capillary or stay in the liver, } \\
\text { stomach, as well as in the organs with tumors }\end{array}$ \\
\hline $7 \sim 12 \mathrm{~mm}$ & Can be ingested by the lungs by intravenous injection \\
\hline $2 \sim 12 \mathrm{~mm}$ & $\begin{array}{l}\text { Can be ingested by capillary network, not only can reach lung, but } \\
\text { also can reach liver and spleen }\end{array}$ \\
\hline $1 \mathrm{~mm}$ & The size is most likely to be devoured by white blood cells \\
\hline $0.1 \sim 0.2 \mathrm{~mm}$ & $\begin{array}{l}\text { Can be injected through the vein, artery or abdominal cavity, and in } \\
\text { the reticuloendothelial system be absorbed by macrophages from } \\
\text { the blood }\end{array}$ \\
\hline$<50 \mathrm{~nm}$ & $\begin{array}{l}\text { Can be transmitted through the liver endothelium or through lymph to } \\
\text { the spleen, and can also reach bone marrow, as well as tumor tissue } \\
\text { and liver }\end{array}$ \\
\hline
\end{tabular}

only the factors of pathophysiology, composition, group type and the groups and affinity of the proteins, but also the factors of size, morphology and structure of the COVID-19. However, based on specialty of the author, in this paper only the possible effect of ultra-small size and super-penetration capability of COVID-19 on some observed phenomena of the COVID-19 were discussed, as described below.

The phenomena that toxicity, transmission speed and diffusion range of the COVID-19 were more than that of Severe acute respiratory syndrome (Sars) virus.

Based on the reported that the diameter of the COVID-19 is in the scope of $60 \sim 140 \mathrm{~nm}$ and that of the Sars virus is in the scope of $60 \sim 220 \mathrm{~nm}$, it is clear that the size of COVID-19 is smaller than that of the Sars virus. So, the author considers that since diameter of the COVID-19 is smaller than that of the Sars virus, it leads to penetration capability of COVID-19 is stronger than that of the Sars virus, which lead to the COVID-19 can more possible to penetrate, invade, and cause more and deeper tissues and organs to be injured by the virus. In result to form the phenomena that the COVID-19 toxicity is higher than that of Sars virus. Therefor the author thinks that when discussing the possible reasons of the toxicity difference between COVID-19 and Sars viruses, not only the factors such as composition, functional groups, molecular morphology and structure of the two viruses should be considered, but also the factor of difference in size and geometry of the two viruses should be simultaneously considered.

On the other hand, because COVID-19 size is smaller than that of the Sars virus, the formed COVID-19 aerosol be also smaller and lighter than the Sars virus aerosol. So that the COVID-19 aerosol can float in the atmosphere for mor longer periods of time, and ultimately under the same airflow the COVID-19 aerosol can floats more faster, farther and wider than that of the Sars virus aerosol. Finally, to become the observed phenomenon that the COVID-19 is faster and wider spread than that of the Sars virus.

According to the recent report, a new virus that the Mutant New Coronaviru (VUI-202103/01) with higher toxicity than the COVID-19 had been found [18]. However, because size of the VUI-202103/01 had not been found, in this article the author cannot discuss that, is or no the VUI-202103/01 a kind nanoparticles and protein nanoparticles, as well as is or not the size of VUI-202103/01 being one of the factors for inferencing toxicity of the COVID-19.

About the questions of the way for infection countermeasure of COVID-19 transmission and the corresponding prevention of viral infection.

It was reported that infection of COVID-19 can be produced by three mode's propagation, that is the direct propagation, aerosol propagation and contact propagation. Direct transmission refers to the infection was caused by direct inhalation of sneezing, coughing, talking droplets and exhaled gases. The aerosol transmission refers to infection caused by inhalation of aerosol formed by inhalation of air

Citation: Wang S (2021) Discussion on the influence of nanoparticle characteristics in New Coronavirus Disease-19 and severe acute respiratory syndrome Coronavirus 2. Int J Nanomater Nanotechnol Nanomed 7(1): 038-042. DOI: https://dx.doi.org/10.17352/2455-3492.000043 
mixed with sneezing, coughing by the inhalation of air mixed with sneezing, coughing and talking droplets of the patient. The contact transmission refers to the infection caused by the contact of the hand contaminated by sneezing, coughing and talking droplets deposited on the surface of the clothing, and the contact with the oral cavity, nasal cavity, eyes and other mucous membranes. Therefore, the corresponding methods, that when going out the person must wear masks and goggles, keep a social distance with others, and wash hands immediately after arriving home for prevent virus infection had been proposed $[19,20]$.

However, based on COVID-19 is a class of nanoparticles possessed not only ultra-small size, but also super-penetration capability. Depending on size of the nanoparticle, the superpenetration capability gives the nanoparticles ability to invade different tissues and organs, as showed in Table 1 [21].

Considering diameter of person's sweat pores is in the range $20,000 \sim 50,000 \mathrm{~nm}$, is hundreds of times bigger than that of the COVID-19 (60 140 nm) [22]. It will be possible let the COVID-19 go to enter the sweat pores and then further into the body. Because average number of the sweat pores in skin is about 100 120 per square centimeter, there are more than 20,000 sweat pores on the face alone [23]. Therefore, the author considers that super-penetration capability of COVID-19 maybe another way for cause the COVID-19 infection.

According to the above, because the super-penetration capability of nanoparticles enables them to invade different tissues and organs of the human body, the COVID-19 as protein nanoparticles may also invade various tissues and organs after entering the human body, which leads to the sequelae of abnormal phenomena such as smell, nervous system, skin and so on in COVID-19 infected patients after the new coronary pneumonia is cured.

Therefore, the author thinks during the formulation of countermeasures to COVID-19 infection, the possible ways that from invading human body through the pores of the skin is also should be considered. Because for a person, the head (including face, neck, ear), hands and the wearing clothes outside are the part that is the longest time to expose in atmosphere. So that, due to avoid COVID-19 infection has produced by the via of the sweat pores, the author suggests that people not only need to use the reported measures, such as wear mask, keep certain distance each other and wash hands immediately after come back from outside etc. [20], but also should wash face, neck and ear immediately after coming back from outside, place the outside wearing clothes separating with other clothes, and wash hands immediately after contacting these clothes again.

About the phenomena that difference time Interval in finding "new crown virus infection", "asymptomatic infection", "suspected case" and "re-infection" within different person.

At the present, nucleic acid testing is widely used to detect COVID-19 infections in the world. And based on the results of nucleic acid testing to determine is "positive (infection)" or "negative (un-infection)", and based on the symptoms of the "positive" person to determine disease degree is "suspected case", "confirmed cases", "symptomatic infected" or "asymptomatic infected", etc. However, some strange phenomena were found, such as for some person at firstly nucleic acid test result is "negative" but second test result is "positive", as well as some person after treatment of SARS-CoV-2 to be found "re-positive", etc. Now these phenomena were explained was happened by differences of detection sampling, detection standard, detection reagent, detection sensitivity as well as the detection accuracy existed among different.

The author considers that COVID-19 is a class of nanoparticles with extremely strong penetration ability, super specific surface and attachment ability that can invade different tissues and organs. Therefore, the COVID-19 can not only enter the human body directly through the respiratory tract and lacrimal gland, but also may be attached to the exposed skin and then drilled into the human body. Because the COVID-19 enters the human body via the respiratory tract and lacrimal gland and then reaches the lung is direct, shorter distance and less time, but the route via penetration and drill into body then reach lung is undirect, longer distance and needing much more time. In result it should take more time to reach the detection concentration of the detection method needed. So, it maybe one more reason for the phenomenon described above.

About the phenomenon that existing difference of time interval from COVID-19 infection until ARS-CoV-2 disease producing for different patients.

Based on that COVID-19 is a class of nanoparticles with super-penetration capability, the author thinks that the different time interval from COVID-19 infection until SARS-CoV-2 disease producing for different patients may be related to the individual difference not only in the age, race, eating habits, antiviral ability and health status of the patients, but also to the difference of the migration routes from the part of the COVID-19 drilled to the site of the lesion and the needed time required among various patients, which as described before.

About the method for prevention and treatment of new coronary pneumonia.

Nowadays, it is the main method to prevent COVID-19 infection by injecting COVID-19 vaccine to promote people's own immunity. For patients who have been infected with COVID-19 and converted into SARS-CoV-2, the drug treatment is the main method.

Due to nanoparticles have many kind applications, including as drug carrier to fabricate nano pharmaceuticals. The nanoparticle carrier not only can disperse well in water to become a stable nanoparticle suspension (Figure 2) $[24,25]$, but also the released drug can keep efficacy unchanged. By using super-penetration capability of the nanoparticles enables nano pharmaceuticals to penetrate human tissues and organs, as shown in Table 1, some target release nano pharmaceuticals have been successfully fabricated, such as the 
nano pharmaceuticals with particle size less than $200 \mathrm{~nm}$ can penetrate blood-brain barrier and gather in the brain to achieve drug release for treating brain tumors [26]; use less than 70 nano pharmaceuticals to kill cancer cells in treating bone marrow [27] and use gelatin and DNA condensed nanoparticles to transport anti-cystic fibrosis gene drugs to the treatment of cystic fibrosis $[28,29]$ and so on.

Considering nano-particles can be used as drug carrier for nano pharmaceuticals. And some nano-particles could be fabricated in the condition of no stabilizers used [30], so the fabricated nano pharmaceuticals not only can be well dispersed in water to become stable nano pharmaceuticals suspension, as shown in Figure 2, but also can keep purity of the nano pharmaceuticals.

On the other hand, based on this kind nano pharmaceuticals can not only keep the efficacy of the drug unchanged, but also can realize continue and target release of the carried drug to achieve high drug utilization [34-36]. For example, by using poly-(glycolide-co-lactide-co-caprolactone) copolymer (PGLC) nanoparticles as drug carrier to fabricate PGLC/5Fluorouracil (PGLC/5-Fu) nano pharmaceuticals to be as a water dispersed anticancer agent [31,32]; the PGLC/Cyclosporin (PGLC/Cs-A) nano pharmaceuticals to be as eye dropping agent for preventing rejection after corneal transplantation [32,33]; etc.

Therefore, the author thinks that can we use characters of the nano pharmaceuticals that can continually to target release drug for prevent COVID-19 infection and treatment of SARS-CoV-2 patients? That is, by means of the method that to spraying or drop killing COVID-19 nano pharmaceuticals agent into nose and eyes, for achieve the purpose to more direct and rapid delivery the drug agent into nose and eyes for killing enter in nose and eyes the COVID-19 to prevention COVID-19 infection, and easy for the drug agent directly enter into lung for achieve treatment of the SARS-CoV-2.

Because this method can not only keep a certain drug concentration at needing to protect site and the lesion site to speed up the cure time, but also can avoid or reduce the side effects of systemic drugs injection way to damage on normal tissues and organs. So by this method will be helpable for getting a better effect of the drug use.

To sum up, based on COVID-19 is a class of protein nanoparticles with super-penetration capability, the author thinks that during explaining many phenomena observed

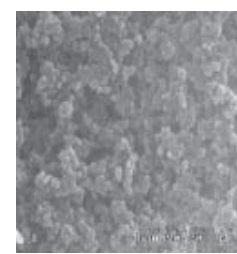

Nano-PGLC

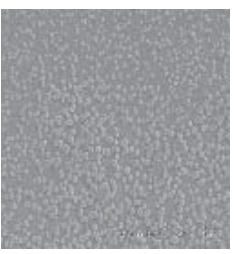

Nano-PGLC suspension

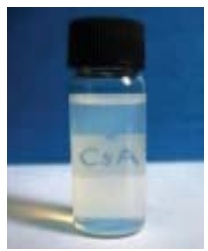

Nano-PGLC/5-Fu suspension

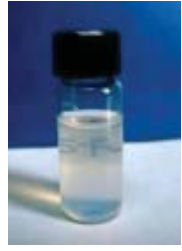

Nano-PGLC/Cs-A suspension in the SARS-CoV-2 epidemic to combine characteristics of the nanoparticles such as ultra-small particles, large specific surface and super-penetration capability etc. of the COVID-19 should be necessary and useful. That is to integrate consider various factors including not only on COVID-19 own characteristics in pathophysiology, structural proteins, affinity and biology etc., but also on other characteristics in physical, chemical, materials, medicine and immunity etc. are necessary. It is hoped that after considered all of the Influencing factors of the COVID-19, to early and clearer understand characteristics of the COVID-19 and promote improving detection, prevention and treatment technology and treatment methods will be achieved. It will be also helpful to early improve and develop new drugs and devices for prevention infection of COVID-19 and treatment the COVID-19.

\section{Conclusions}

Based on ultra-small size of the COVID-19, it should belong a kind of protein nanoparticles and possess characters of superpenetration capability. Therefore, the ultra-small size and super-penetration possibly are one of the factors for produce following phenomena. That is (1) toxicity, transmission speed and diffusion range of the COVID-19 were more than that of Severe virus; (2) For different person, existed different time interval between COVID-19 infection and discover; (3) For different person existed different time interval in "new crown virus infection", "asymptomatic infection", "suspected case" and "re-infection" produced, and (4) the different time interval from COVID-19 infection to SARS-CoV-2 disease producing in different person. Due to avoid and prevent COVID-19 infection, as well as to treat SARS-CoV-2, to wash face, neck and ear immediately after coming back from outside, place the outside wearing clothes separating with other clothes, and wash hands immediately after contacting these clothes again are also important. To use relative nano pharmaceuticals for prevention COVID-19 infection and treatment of SARS-CoV-2 was suggested. So that, to develop cooperative research among different subject and consider more factors for earlier and clearer know characteristics of the COVID-19 and the method for promote improving detection, prevention and treatment technology and treatment is necessary.

\section{References}

1. RHuang B (2019) Severe acute respiratory syndrome coronavirus 2: The Ad vantages and Disadvantages of Antibody.

2. COVID-19 deaths in the world.

3. Kissler SM, Tedijanto C, Goldestein E, Grad YH, Lipsitch M (2020) Projecting the transmission dynamics of SARS-CoV-2 through the postpandemic period. Science 368: 860-868. Link: https://bit.ly/3svywEx

4. Characteristic of nanoparticle.

5. What are the main properties of nano-particles.

6. Huang $Y$, Yang $C, X u X, X u$ W, Liu S (2020) Structural and functional properties of SARS-CoV-2 spike protein: potential antivirus drug development for COVID-19. Acta Pharmacol Sin 41: 1141-1149. Link: https://go.nature.com/3frr3T6

7. Kumar R, Francis V, McPherson P (2020) SARS-CoV-2 uses clathrin mediated endocytosis to gain access into cells. BioRxiv Prepr Link: https://bit.ly/39rET42

Citation: Wang S (2021) Discussion on the influence of nanoparticle characteristics in New Coronavirus Disease-19 and severe acute respiratory syndrome Coronavirus 2. Int J Nanomater Nanotechnol Nanomed 7(1): 038-042. DOI: https://dx.doi.org/10.17352/2455-3492.000043 
8. Matsuyama S, Ujike M, Morikawa S, Tashiro M, Taguchi F (2005) Proteasemediated enhancement of severe acute respiratory syndrome coronavirus infection. Proc Natl Acad Sci 102: 12543-12547. Link: https://bit.ly/3ubyZw9

9. Sungnak W, Huang N, Bécavin C Berg M, Queen R, et al. (2020) SARS-CoV-2 entry factors are highly expressed in nasal epithelial cells together with innate immune genes. Nat Med 26: 681-687. Link: https://bit.ly/3u6WSox

10. Xie P, Ma W, Tang H, Liu D (2020) Severe COVID-19: A Review of Recent Progress With a Look Toward the Future. Front Public Health 8: 189. Link: https://bit.ly/3sCCTgX

11. Vankadari N (2020) Structure of Furin Protease Binding to SARS-CoV-2 Spike Glycoprotein and Implications for Potential Targets and Virulence. J Phys Chem Lett 11: 6655-6663. Link: https://bit.ly/3rBNFmz

12. Shang J, Ye G, Shi K, Wan Y, Luo C, et al. (2020) Structural basis of receptor recognition by SARS-CoV-2. Nature 581: 221-224. Link: https://bit.ly/3dbv5fC

13. Kirchdoerfer RN, Cottrell CA, Wang N, Pallesen J, Yassine HM, et al. (2016) Prefusion structure of a human coronavirus spike protein. Nature 531: 118-121. Link: https://go.nature.com/3sCPOdY

14. Cantuti-Castelvetri L, Ojha R, Pedro LD, Djannatian M, Franz J, et al. (2020) Neuropilin-1 facilitates SARS-CoV-2 cell entry and infectivity. Science 370 856-860. Link: https://bit.ly/2PjIBan

15. Sun GF, Shen H, Yang F, Zhang LC, Wang SG, et al. (2018) Discussion on biosafety of nanomaterials and nanoform preparations. Nano Research (Reviewed)

16. Shen H, Yang F, Bei JZ, Wang SG (2020) Polymeric Nanoparticles. Polymer Bulletin 1-14.

17. Panyam J, Labhasetwar V (2003) Biodegradable nanoparticles for drug and gene delivery to cells and tissue. Adv Drug Deliv Rev 55: 329-347. Link: https://bit.ly/3cCOcSO

18. Mutant Coronavirus Found in UK. Science. Link: https://bit.ly/3cxMcJG

19. Prevention of COVID-19. Latest research progress of COVID-19 (No .9). Link: https://bit.ly/2QHARy2

20. Qiaolingling R (2018) WHOThe public prevent new coronavirus. Link: https://bit.ly/3cycgUU

21. Shengguo W, Jianzhong B (2004) Materials Science and Engineering Manua ,12th chapter ,12: 72-79. China Society of Materials Research, Chemical Industry Press, material Science and Engineering Publishing Center.

22. What is the diameter of a person's pores

23. Lu Z, Bei JZ, Wang SG (1999) A Method for Preparation of Polymeric Nanocapsules without Stabilizer. J Control Release 61: 107-112. Link: https://bit.ly/3dkVMP8

24. Characteristics and uses of nanomaterials.

25. Asbach B, Wagner R (2017) Particle-based delivery of the HIV envelope protein. Curr Opin HIV AIDS 12: 265-271. Link: https://bit.ly/3czs3CX

26. Moghimi SM, Hunter AC, Murray JC (2001) Long-circulating and targetspecific nanoparticles: theory to practice. Pharmacol Rev 53: 283-318. Link: https://bit.ly/2PEbmgO

27. Stolnik S, Heald CR, Neal J, Garnett MC, Davis SS, et al. (2001) Polylactidepoly(ethylene glycol) micellar-like particles as potential drug carriers: production, colloidal properties and biological performance. J Drug Target 9: 361-378. Link: https://bit.ly/3djjbAv
28. Lobenberg R, Kreuter J (1996) Macrophage targeting of azidothymidine: a promising strategy for AIDS therapy. AIDS Res Hum Retroviruses 12: 1709 1715. Link: https://bit.ly/31tm0cM

29. Zhang HW, Cui WJ, Bei JZ, Wang SG (2007) Preparation and drug release behaviors of 5-Fluorouracil loaded poly(glycolide-co-lactide-co-caprolactone) nanoparticles. J Appl Polym Sci (Journal of Applied Polymer Science) 106 3757-3767. Link: https://bit.ly/3cBmluS

30. Wang SG, Chen HL, Cai Q, Bei JZ (2001) Degradation and 5-Fliorouracil Release Behavior in vitro of Polycaprolactone/Poly-(ethylene glycol)/Polylactide Tricomponent Copolymer. Polymer Advanced Technologies 12: 253-258. Link: https://bit.ly/3rGGpG8

31. Xie LX, Shi WY, Wang ZY, Bei JZ, Wang SG (2001) Prolongation of Cornea Allograft Survival Using Cyclosporine in a Polylactide-co-glycolide Polymer Cornea 20: 748-752. Link: https://bit.ly/3cx6D9E

32. Kreuter J, Alyautdin RN, Kharkevich DA, Aivanov A (1995) Passage of peptide through the blood-brain barrier with colloidal polymer particles (nanoparticles). Brain Res 674: 171-174. Link: https://bit.ly/20QHsq9

33. What nanopharmaceuticals are targeted

34. Zimmer A, Mutschler E, Lambrecht G, Mayer D, Kreuter J (1994) Pharmacokinetic and pharmacodynamic aspects of an ophthalmic pilocarpine nanoparticle-delivery-system. Pharm Res 11: 1435-1442. Link: https://bit.ly/39qeeoz

35. Shi WY, Xie J, Wang SG (2002) Effects of cyclosporine A sustained release system on inhibition of immune rejection in rat corneal transplantation. Chinese Journal of Ophthalmology 38: 502-505

36. Li DS, Yoon SJ, Pelivanov I, Frenz M, O'Donnell M, et al. (2017) Polypyrrolecoated perfluorocarbon nanoemulsions as a sono-photoacoustic contrast agent. Nano Lett 17: 61981-6194. Link: https://bit.ly/3sCQHIm

\section{Discover a bigger Impact and Visibility of your article publication with}

\section{Peertechz Publications}

\section{Highlights}

* Signatory publisher of ORCID

* Signatory Publisher of DORA (San Francisco Declaration on Research Assessment)

- Articles archived in worlds' renowned service providers such as Portico, CNKI, AGRIS, TDNet, Base (Bielefeld University Library), CrossRef, Scilit, J-Gate etc.

* Journals indexed in ICMJE, SHERPA/ROMEO, Google Scholar etc.

* OAI-PMH (Open Archives Initiative Protocol for Metadata Harvesting)

* Dedicated Editorial Board for every journal

* Accurate and rapid peer-review process

* Increased citations of published articles through promotions

* Reduced timeline for article publication

Submit your articles and experience a new surge in publication services (https://www.peertechz.com/submission).

Peertechz journals wishes everlasting success in your every endeavours.

Copyright: @ 2021 Wang S. This is an open-access article distributed under the terms of the Creative Commons Attribution License, which permits unrestricted use, distribution, and reproduction in any medium, provided the original author and source are credited.

Citation: Wang S (2021) Discussion on the influence of nanoparticle characteristics in New Coronavirus Disease-19 and severe acute respiratory syndrome Coronavirus 2. Int J Nanomater Nanotechnol Nanomed 7(1): 038-042. DOI: https://dx.doi.org/10.17352/2455-3492.000043 